The University of Maine

\title{
DigitalCommons@UMaine
}

Maine-Syracuse Longitudinal Papers

Maine-Syracuse Longitudinal Study

2005

\section{Homocysteine, type 2 diabetes mellitus, and cognitive performance: The Maine-Syracuse Study}

Michael A. Robbins

University of Maine - Main, robbins@maine.edu

Merrill F. Elias

University of Maine - Main, mfelias@maine.edu

Marc M. Budge

Suzanne L. Brennan

Penelope K. Elias

Follow this and additional works at: https://digitalcommons.library.umaine.edu/ longitudinal_papers

Part of the Cognitive Psychology Commons

\section{Repository Citation}

Robbins, M. A., Elias, M. F., Budge, M. M., Brennan, S. L., \& Elias, P. K. (2005). Homocysteine, type 2 diabetes mellitus, and cognitive performance: The Maine-Syracuse Study. Clinical chemical and laboratory medicine, 43(10), 1101-1105.

This Article is brought to you for free and open access by DigitalCommons@UMaine. It has been accepted for inclusion in Maine-Syracuse Longitudinal Papers by an authorized administrator of DigitalCommons@UMaine. For more information, please contact um.library.technical.services@maine.edu. 


\section{Homocysteine, type 2 diabetes mellitus, and cognitive performance: The Maine-Syracuse Study}

\author{
Michael A. Robbins ${ }^{1, *}$, Merrill F. Elias ${ }^{1,2}$, Marc \\ M. Budge ${ }^{3}$, Suzanne L. Brennan ${ }^{1}$ and Penelope \\ K. Elias ${ }^{1,2}$
}

${ }^{1}$ Department of Psychology, University of Maine, Orono, ME, USA

${ }^{2}$ Statistics and Consulting Unit, Department of Mathematics and Statistics, Boston University, Boston, MA, USA

${ }^{3}$ Department of Geriatric Medicine, Australian National University Medical School, Canberra, Australia

\begin{abstract}
Type 2 diabetes mellitus and higher total plasma homocysteine concentrations are each associated with an increased incidence of cardiovascular disease and with diminished cognitive performance. Relations between homocysteine concentrations and cardiovascular disease incidence are stronger in the presence of type 2 diabetes mellitus. Therefore, we hypothesized that relations between homocysteine concentrations and cognitive performance would be stronger in the presence of type 2 diabetes. We related homocysteine concentrations and cognitive performance on the Mini-Mental State Examination in 817 dementiaand stroke-free participants of the Maine-Syracuse Study, 90 of whom were classified with type 2 diabetes mellitus. Regardless of statistical adjustment for age, sex, gender, vitamin co-factors (folate, vitamin $B_{6}$, vitamin $\left.B_{12}\right)$, cardiovascular disease risk factors, and duration and type of treatment for type 2 diabetes mellitus, statistically significant inverse associations between homocysteine concentrations and cognitive performance were observed for diabetic individuals. The weaker inverse associations between homocysteine concentrations and cognitive performance obtained for non-diabetic individuals were not robust to statistical adjustment for some covariates. Interactions between homocysteine concentrations and type 2 diabetes mellitus are observed such that associations between homocysteine and cognitive performance are stronger in the presence of diabetes.
\end{abstract}

Keywords: cardiovascular risk factors; cognitive performance; diabetes mellitus; folate; homocysteine; vitamin $\mathrm{B}_{12}$; vitamin $\mathrm{B}_{6}$.

*Corresponding author: Michael A. Robbins, PhD, Department of Psychology, 5742 Little Hall, University of Maine, Orono, ME 04469-5742, USA

Phone: + 1-207-581-2051, Fax: +1-207-581-6128,

E-mail: mar@umit.maine.edu

\section{Introduction}

Increments in total homocysteine (tHcy) concentrations are independently associated with increasing risk for cerebrovascular and cardiovascular disease (CVD) (1-4). Similarly, diabetes mellitus is a known risk factor for atherosclerosis, peripheral vascular disease, and CVD (5). Moreover, there is evidence that high levels of thcy contribute to the acceleration of CVD in diabetics (6). Levels of tHcy are sometimes, but not always, higher in diabetics (7).

There is substantial evidence that the presence of diabetes mellitus is related to lower cognitive performance $(5,8)$. Also, several studies have shown that tHcy levels are inversely related to cognitive performance within the normal range of cognitive ability (9-13). Consequently, we felt it important to examine interactions between diabetes mellitus and tHcy as they relate to cognitive performance. We did so by stratifying by presence and absence of type 2 diabetes mellitus (DM) and examining relations between tHcy and cognitive performance within these groups.

When undertaking these studies it is important to statistically adjust associations between tHcy and cognitive performance for serum folate, vitamin $B_{6}$ and vitamin $B_{12}$ concentrations, CVD risk factors, history of CVD morbidity, and depressed $\operatorname{mood}(5,10$, 14).

The Maine-Syracuse Study (15) provides data with respect to tHcy, DM, and the covariates of interest. Consequently, we tested the following hypotheses using individuals from this study sample who were clinically stroke- and dementia-free: 1) tHcy and the presence of DM would interact such that relations between tHcy and cognitive performance would be of a higher magnitude for diabetics than for non-diabetics; and 2) relations between tHcy and cognitive performance, for diabetics and non-diabetics, would be attenuated by adjustment for vitamin cofactors and by adjustment for CVD risk factors, depressed mood, and CVD morbidity.

\section{Materials and methods}

\section{Design}

The Maine-Syracuse Study provided the community-dwelling study sample $(15,16)$. At the most recent longitudinal examination (April 2001 to January 2005), tHcy and vitamin cofactor (i.e., vitamins $B_{6}, B_{12}$ and folate) blood concentrations were obtained for 854 individuals. The vitamin cofactor data and data on blood pressure (BP), other CVD risk factors, depressed mood, and CVD morbidity constituted the set of covariates for the present study. Informed consent was obtained from all participants. The consent forms and pro- 
tocol were approved by the institutional Review Boards for Human Research at the University of Maine and at the State University of New York Upstate Medical University.

\section{Subjects}

Hospital or physician records and records of a clinical BP examination and detailed medical interview were available for all 854 study participants, of whom 37 were excluded for the following reasons: 1$)$ probable dementia $(n=8)$ assessed by a committee of psychologists and a physician, using the criteria of the National Institute of Neurological and Communicative Disorders and Stroke and the Alzheimer's Disease and Related Disorders Association (17); or 2) a confirmed history of clinical stroke $(n=29)$. The final sample consisted of the remaining 817 participants.

\section{Procedure}

Participants were admitted to the study center the morning following a fast from midnight. The visit began with a comprehensive medical history and a physical examination that included the drawing of a blood sample and BP measurement. Blood samples were collected in standard EDTA tubes for plasma tHcy and plasma $B_{6}$ determinations and in serum separator tubes (gel and clot activator) for serum determinations.

The medical history was verified via diagnostic records and/or physician contact with permission of the participant. After a light breakfast, a test protocol that included the Center for Epidemiological Studies Depression Scale (CES-D) (18) and the Mini-Mental State Examination (MMSE) (19) was administered by a psychometrician.

Blood samples were delivered, on ice, to Centrex Clinical Laboratories, Syracuse, New York, for processing and sameday assay of serum folate, serum vitamin $B_{12}$, a lipid panel, triglycerides, glucose and creatinine. Serum folate and serum vitamin $B_{12}$ concentrations were determined using a paramagnetic-particle chemiluminescent immunoassay (ADVIA Centaur, Bayer HealthCare, Tarrytown, NY, USA). Glucose was determined by a colorimetric test and serum creatinine was determined using a two-point rate test type (Vitros Chemistry System, Johnson and Johnson, New Brunswick, NJ, USA). Coefficients of variation for all these procedures were less than $5.0 \%$.

Plasma samples used for determination of thcy and vita$\min B_{6}$ (plasma pyridoxal $5^{\prime}$-phosphate) were stored at $-40^{\circ} \mathrm{C}$ until a batch of $100-150$ samples was collected. Plasma tHcy concentrations were determined at the Department of Pharmacology, University of Oxford, using a fluorescence polarization immunoassay (Axis-Shield, Dundee, UK) on an Abbott IMx auto-analyzer (Abbott Laboratories, Chicago, IL, USA) (20). The coefficient of variation for the tHcy assays was less than $3.5 \%$.

Vitamin $\mathrm{B}_{6}$ concentrations were determined at the Nutritional Biochemistry Laboratory, Medical Research Council Human Nutrition Research (Cambridge, UK) using a Waters Empower 2010-controlled high-performance liquid chromatography system (HPLC) (Watford, UK) and a Waters 474 scanning florescence detector. The HPLC system was a Waters 2695 Alliance separation module (Waters Symmetry Shield RP8, $5 \mu \mathrm{m}, 4.6 \times 250 \mathrm{~mm}$ ). Assay control was via a dual-level lyophilized standard from ChromSystems diagnostics by HPLC (Munich, Germany). Coefficients of variation for the plasma pyridoxal $5^{\prime}$-phosphate assays were $3.75 \%$ or less.

\section{Cognitive test and predictor variables}

The MMSE is widely used as a global screening measure of cognitive functioning $(19,21)$. Questions address such cognitive functions as orientation to time and place, registration and recall, attention and calculation, language, and visual construction. Scores can range from 0 to a maximum of 30 .

Plasma tHcy $(\mu \mathrm{mol} / \mathrm{L})$ was the predictor variable in relation to cognitive performance. Most participants in the DM group were classified on the basis of treatment with insulin $(n=32)$ or oral antidiabetic agents $(n=57)$. One additional participant assigned to the DM group was classified on the basis of a fasting glucose level at the visit of $>200 \mathrm{mg} / \mathrm{dL}(11.1$ $\mathrm{mmol} / \mathrm{L}$ ) with self-reported symptoms of polyuria and polydipsia (22). Results described below were the same when this participant, whose fasting glucose level was 11.4 $\mathrm{mmol} / \mathrm{L}$, was excluded from analyses. None of the participants were classified as type 1 diabetics. Enzyme cofactor covariates were serum folate $(\mathrm{nmol} / \mathrm{L})$, vitamin $B_{6}(\mathrm{nmol} / \mathrm{L})$, and vitamin $B_{12}(\mathrm{pmol} / \mathrm{L})$. Demographic and candidate CVD covariates were as follows: age (years); education (years); gender; systolic BP ( $\mathrm{mm} \mathrm{Hg}$ ); cigarette smoking (number/ week); total cholesterol ( $\mathrm{mmol} / \mathrm{L})$; alcohol consumption (ounces/week); body mass index (BMI, $\mathrm{kg} / \mathrm{m}^{2}$ ); coffee consumption (cups/day); mild renal dysfunction; history of CVD morbidity; and depressed mood. Mild renal dysfunction was defined as an estimated creatinine clearance using the Cockcroft-Gault formula (23) of $<60 \mathrm{~mL} / \mathrm{min}(1 \mathrm{~mL} / \mathrm{s}$ ) (24). History of CVD morbidity was defined as a confirmed record of myocardial infarction, coronary artery disease, congestive heart failure, angina pectoris, or transient ischemic attack. Depressed mood was defined as a CES-D score of 16 or greater (19).

\section{Statistical analyses}

The MMSE scores were skewed. We transformed MMSE scores to natural log values and compared results of analyses using log-transformed and raw MMSE scores. Because results were the same, we report results for the raw scores only. Raw scores were transformed to z-scores. Distributions of folate, vitamin $B_{6}$, and vitamin $B_{12}$ concentrations, and cigarettes smoked/week were also skewed. A natural log transformation was calculated for these covariates and used for analyses.

Associations of tHcy with MMSE scores (z-transformed) for the DM and non-DM groups were examined in a series of multivariable regression models. In separate analyses, tHcy $\times D M$ status interaction effects were tested to further validate the a priori stratification. The first (basic) model included age, education, and gender. Subsequent models added additional covariates to the basic model as follows: 1 ) folate; 2) vitamin $\mathrm{B}_{6}$; 3) vitamin $\mathrm{B}_{12}$; and 4) risk factor covariates chosen via a backward elimination regression procedure (described in Results below).

\section{Results}

\section{Sample descriptives}

Table 1 summarizes sample characteristics. Compared to the non-DM participants, participants with DM had significantly higher tHcy concentrations, lower MMSE scores, and exhibited a higher prevalence of obesity, CVD morbidity, and depressed mood. Furthermore, the DM group was older, had lower levels of education, lower levels of folate, higher systolic BP, and higher BMI. 
Table 1 Sample characteristics.

\begin{tabular}{|c|c|c|c|c|c|c|c|c|c|c|}
\hline \multirow[t]{2}{*}{ Variable } & \multicolumn{3}{|c|}{ Full sample $(n=817)$} & \multicolumn{3}{|c|}{ Non-DM group $(\mathrm{n}=727)$} & \multicolumn{3}{|c|}{ DM group $(n=90)$} & \multirow[t]{2}{*}{$\mathrm{p}$} \\
\hline & Mean & SD & $\%$ & Mean & SD & $\%$ & Mean & SD & $\%$ & \\
\hline $\mathrm{tHcy}, \mu \mathrm{mol} / \mathrm{L}$ & 10.0 & 3.8 & & 9.8 & 3.6 & & 11.8 & 5.2 & & 0.001 \\
\hline MMSE score & 28.4 & 1.8 & & 28.5 & 1.6 & & 27.1 & 2.6 & & 0.001 \\
\hline Age, years & 61.8 & 12.6 & & 61.5 & 12.7 & & 64.7 & 11.0 & & 0.03 \\
\hline Education, years & 14.6 & 2.7 & & 14.8 & 2.7 & & 13.4 & 2.8 & & 0.001 \\
\hline Folate, $\mathrm{nmol} / \mathrm{L}$ & 38.5 & 11.8 & & 38.8 & 11.6 & & 36.2 & 13.3 & & 0.06 \\
\hline Vitamin $\mathrm{B}_{6}, \mathrm{PLP}^{\mathrm{a}}, \mathrm{nmol} / \mathrm{L}$ & 95.5 & 93.2 & & 97.3 & 93.4 & & 80.9 & 91.3 & & 0.12 \\
\hline Vitamin $\mathrm{B}_{12}, \mathrm{pmol} / \mathrm{L}$ & 390.6 & 212.9 & & 390.7 & 213.4 & & 389.6 & 210.4 & & 0.96 \\
\hline Systolic BP, mm Hg & 131.3 & 21.9 & & 130.3 & 21.7 & & 139.3 & 21.7 & & 0.001 \\
\hline Diastolic BP, mm Hg & 70.7 & 10.0 & & 70.6 & 10.1 & & 71.9 & 8.5 & & 0.25 \\
\hline Alcohol, ounces/week & 1.5 & 2.8 & & 1.6 & 2.9 & & 0.7 & 1.7 & & 0.003 \\
\hline Cigarettes, number/week & 9.0 & 36.7 & & 9.2 & 36.9 & & 7.5 & 36.0 & & 0.65 \\
\hline Total cholesterol, $\mathrm{mmol} / \mathrm{L}$ & 5.3 & 1.0 & & 5.3 & 1.0 & & 4.8 & 1.2 & & 0.001 \\
\hline Body mass index, $\mathrm{kg} / \mathrm{m}^{2}$ & 29.4 & 6.1 & & 28.8 & 5.5 & & 34.1 & 8.0 & & 0.001 \\
\hline Coffee, cups/day & 1.8 & 1.9 & & 1.9 & 2.0 & & 1.4 & 1.4 & & 0.03 \\
\hline Creatinine clearance $^{\mathrm{b}}, \mathrm{mL} / \mathrm{s}$ & 1.5 & 0.6 & & 1.5 & 0.6 & & 1.5 & 0.7 & & 0.75 \\
\hline Gender (female) & & & 58.3 & & & 58.6 & & & 56.2 & 0.66 \\
\hline Obesity (BMI $\left.\geq 29.9 \mathrm{~kg} / \mathrm{m}^{2}\right)$ & & & 45.6 & & & 42.0 & & & 75.3 & 0.001 \\
\hline CVD morbidity ${ }^{d}$ & & & 16.2 & & & 13.5 & & & 38.2 & 0.001 \\
\hline Mild renal dysfunction ${ }^{\mathrm{e}}$ & & & 16.8 & & & 16.1 & & & 22.5 & 0.14 \\
\hline Depressed mood & & & 10.4 & & & 9.4 & & & 19.3 & 0.008 \\
\hline
\end{tabular}

a Pyridoxal 5'-phosphate. ${ }^{\mathrm{b}}$ Estimated using the Cockcroft-Gault Formula (23). ${ }^{\mathrm{c}}$ Current antidiabetic medication treatment, or fasting glucose levels of $200 \mathrm{mg} / \mathrm{dL}$ (11.1 mmol/L) or greater. ${ }^{\mathrm{d}}$ CVD includes the following diagnostic categories: 1$)$ myocardial infarction, $\mathrm{n}=37(4.5 \%) ; 2)$ coronary artery disease, $\mathrm{n}=69(8.4 \%) ; 3)$ congestive heart failure, $\mathrm{n}=21(2.6 \%) ; 4)$ angina pectoris, $\mathrm{n}=52(6.4 \%)$; and 5) transient ischemic attack, $\mathrm{n}=31(3.8 \%)$. ${ }^{\text {e }}$ Estimated creatinine clearance $<1 \mathrm{~mL} / \mathrm{s}$.

\section{Preliminary analyses}

Tests of Cook's distance indicated that no individual participant in either the DM or the non-DM group significantly $(p>0.95)$ influenced the regression coefficients presented below (25). Neither interactions of tHcy with age nor quadratic effects of tHcy were statistically significant in relation to MMSE scores for either the DM group $(p>0.80)$ or the non-DM group $(p>0.22)$.

DM individuals were less likely than non-DM individuals to arrive for their examination having fasted for 9 or more hours $(20.0 \%$ vs. $4.0 \%$, respectively; $p<0.001)$. However, tHcy concentrations $(p>0.40)$ and MMSE scores $(p>0.30)$ did not differ on the basis of fasting status for either the DM or the non-DM group. Furthermore, fasting status, as well as two of the candidate risk-factor covariates (alcohol consumption and body mass index), failed to meet backward elimination criteria for inclusion $(p<0.20)$ in the final risk-factor model. The covariates retained for the final risk-factor model were systolic BP, cigarette smoking, total cholesterol, coffee consumption, mild renal dysfunction, CVD morbidity, and depressed mood.

For each of the five models tested there was a statistically significant interaction of tHcy $\times$ DM status $(p<0.05)$. Thus, we proceeded to stratify by the presence or absence of DM for all further analyses as planned.

\section{Major findings}

Associations of tHcy and MMSE scores were stronger for the DM group than for the non-DM group (Table 2). Introduction of the covariates, particularly the risk factor covariates, attenuated the associations of tHcy and MMSE scores for both groups. Nevertheless, the associations of tHcy and MMSE scores remained stronger for the DM group than the non-DM group. For example, each $5-\mu \mathrm{mol} / \mathrm{L}$ increment in tHcy is associated with a one-third of a standard deviation decrement in MMSE scores for the DM group, but only a one-twentieth of a standard deviation decrement in MMSE scores for the non-DM group.

Table 2 Regression coefficients $(\beta)$ and standard errors $(\mathrm{SE} \beta)$ showing the associations between tHcy $(1-\mu \mathrm{mol} / \mathrm{L}$ increments) and MMSE test scores in SD units (z-scores) for the DM and non-DM groups.

\begin{tabular}{lcc}
\hline Model & Group \\
\cline { 2 - 3 } & DM & Non-DM \\
\hline Basic & & \\
$\beta$ & $-0.082^{* *}$ & $-0.022^{*}$ \\
SE $\beta$ & 0.028 & 0.010 \\
Basic +folate & & \\
$\beta$ & $-0.078^{* *}$ & -0.018 \\
SE $\beta$ & 0.029 & 0.010 \\
Basic $+B_{6}$ & & \\
$\beta$ & $-0.071^{*}$ & $-0.020^{*}$ \\
SE $\beta$ & 0.028 & 0.010 \\
Basic $+B_{12}$ & & \\
$\beta$ & $-0.082^{* *}$ & -0.017 \\
SE $\beta$ & 0.028 & 0.010 \\
Basic + risk factors + CVD morbidity & & \\
$\beta$ & $-0.067^{*}$ & -0.013 \\
SE $\beta$ & 0.034 & 0.010 \\
\hline
\end{tabular}

${ }^{*} p<0.05 ;{ }^{* *} p<0.01$. Basic model: age, education, gender. Risk factors: cigarette smoking, systolic $\mathrm{BP}$, mild renal dysfunction, total cholesterol, coffee consumption, depressed mood. 
None of the vitamin cofactors or the risk factor covariates were related to MMSE scores for the DM group (all $p>0.07$ ). However, several covariates showed significant associations with MMSE scores for the non-DM group: 1) folate (natural log) ( $\beta=$ $0.226, \mathrm{SE} \beta=0.099, \mathrm{p}<0.05) ; 2$ ) cigarette smoking (natural $\log )(\beta=-0.099, \operatorname{SE} \beta=0.026, p<0.001)$; and 3) total cholesterol $(\beta=0.084, \mathrm{SE} \beta=0.032, \mathrm{p}<0.01)$.

Additional analyses were conducted in order to assess whether adjustment for self-reported duration of diabetes or type of treatment attenuated associations of tHcy and MMSE scores for the DM group. Self-reported duration, which ranged from 0 to 43 years $(M=9.6, S D=8.8)$, was positively correlated with tHcy $(r=0.46, p<0.001)$, even with adjustment for age and gender, but unrelated to MMSE scores $(p>0.90)$. With respect to type of treatment, DM participants treated with insulin $(n=32)$ did not differ either in MMSE scores $(p>0.20)$ or in tHcy concentrations $(p>0.45)$ from DM participants treated with oral antidiabetic drugs $(n=57)$. Attenuation of regression coefficients relating tHcy and MMSE ranged from $0 \%$ to $14 \%$ for duration and $0 \%$ to $8 \%$ for treatment modality across the five models. However, the pattern of significant inverse relations for tHcy and MMSE scores for the DM group was unchanged.

Several previous studies of tHcy using the MMSE have screened out participants scoring under $24(9$, 12 ), the cut-off point below which further diagnostic evaluation for mild to more severe cognitive impairment or probable dementia is indicated (21). After screening out participants scoring under 24 on the MMSE $(n=25)$, we repeated the series of analyses detailed above. Results for the remaining non-DM group ( $n=15$ excluded) were attenuated such that significant associations of tHcy and MMSE z-scores were no longer observed (all $p>0.25$ ). These exclusions $(n=10)$ also attenuated results for the remaining DM group, for which regression coefficients were reduced by a range from $5 \%$ to $29 \%$ in various models. However, associations of tHcy and MMSE z-scores remained statistically significant for all models with one exception. With statistical adjustment for the demographic and risk factor covariates, the association of tHcy and MMSE z-scores was non-significant ( $\beta=-0.044, \operatorname{SE} \beta=0.028, p=0.12)$.

In a final set of analyses, we stratified on the basis of tHcy concentrations in order to compare MMSE scores for DM and non-DM participants with lower or higher tHcy concentrations. A similar pattern of MMSE results was observed: 1) whether tHcy was stratified at the median $(9.1 \mu \mathrm{mol} / \mathrm{L})$, the mean (10 $\mu \mathrm{mol} / \mathrm{L})$, or a higher value $(12.5 \mu \mathrm{mol} / \mathrm{L}) ; 2)$ no matter which covariates were included in the model; and 3) whether individuals with MMSE scores under 24 were excluded. The most discrepant MMSE means were shown by the group with DM and high tHcy. For instance, with tHcy stratified at $10 \mu \mathrm{mol} / \mathrm{L}$ and adjustment for the demographic and risk factor covariates, MMSE means were as follows: 1) non-DM, low tHcy, $\mathrm{M}=-0.014$; 2) non-DM, high tHcy, $\mathrm{M}=-0.082$; 3) $\mathrm{DM}$, low tHcy, $\mathrm{M}=-0.027$; and 4) $\mathrm{DM}$, high tHcy, $\mathrm{M}=-0.730$.

\section{Discussion}

Our results indicate that associations between tHcy and performance on a global screening test of cognitive performance are stronger for diabetic than for non-diabetic individuals. In this respect the present results parallel those indicating that tHcy is related to heightened risk of CVD for diabetic relative to nondiabetic individuals (6). Becker et al. (7) have suggested that these CVD data indicate that DM and tHcy have adverse synergistic effects. Our results are consistent with this interpretation in that the poorest mean performance levels were consistently observed for individuals with DM and high tHcy levels.

Results were mixed in the few previous studies that have investigated tHcy and cognitive function in relation to DM. A three-level glycemic status variable (normal fasting glucose vs. impaired fasting glucose vs. diabetes) did not interact with tHcy in relation to cognitive function in a sample of 1241 subjects aged 61-73 years, although an overall association of tHcy and cognitive function was reported (14). Inverse associations were reported between tHcy and MMSE scores in a clinical sample of 50 DM patients (26).

Although DM tends to cluster with other CVD risk factors, there is an adverse impact of DM on cognition that is independent of these other risk factors (5). Although broadly attributable to impaired metabolic control (i.e., hypoglycemia, hyperglycemia, hyperinsulinemia), specific bases for the association of DM with cognition are poorly understood (5). High tHcy does not always cluster with other CVD risk factors (27), and our results converge with those of recent studies $(10,14)$ indicating that tHcy associations with cognitive functioning cannot simply be attributed to the effects of these other risk factors.

Elevation in tHcy is seen in the presence of deficits in the vitamin cofactors, folate, vitamin $B_{6}$, and vita$\min B_{12}(28,29)$. Since 1996 , overall reductions in tHcy concentrations and a decreased prevalence of high homocysteine values have been observed in the United States due to fortification of enriched grain products with folic acid (30). Nevertheless, in this study, tHcy concentrations obtained between 2001 and 2005 were inversely associated with cognitive performance. Furthermore, these associations do not appear to be attributable to vitamin cofactor status because they were observed despite statistical control for concentrations of vitamin $B_{6}$ and vitamin $B_{12}$, as well as folate (10).

Exclusion of participants who scored under 24 on the MMSE resulted in attenuation of associations between tHcy and MMSE scores, regardless of which covariates were included in the model. However, for the DM group these associations remained statistically significant for all models except one. For the model that included risk factor and CVD covariates, the association between tHcy and MMSE scores was rendered statistically non-significant $(p=0.12)$. This result could be attributed to the reduction in sample size $(n=80)$ after these exclusions for the DM group, the reduced range of outcome (MMSE) scores, or the 
fact that the poorest-performing participants were excluded. A recent study with over 2800 participants reported significant inverse associations between tHcy and MMSE scores, regardless of whether MMSE scores under 24 were excluded (31). Furthermore, these results were reported for a model that included many of the risk factor covariates that we used (31).

We hypothesized and found that statistical adjustment for the vitamin cofactors, as well as the CVD risk factors, CVD morbidity, and depressed mood, attenuated associations between tHcy and cognitive performance to varying degrees. For the DM group, however, significant inverse associations persisted. These results may be attributable to the neurotoxic effects of tHcy (32-34). The adverse effects of tHcy on endothelial function have been proposed as the basis for the association of tHcy with CVD risk (35), and the accelerated CVD risk for diabetics (7). Elevations in tHcy can also sensitize neurons to the adverse effects of oxidative stress (32). Oxidative stress is associated with DM due to hyperglycemia (5). Although speculative, this phenomenon might possibly serve as the basis by which tHcy and DM interact to impact cognitive function and promote neurodegenerative disorders (32).

Our participants with DM had higher tHcy levels than non-DM participants. We also found that increasing duration of diabetes was related to higher tHcy levels. However, neither duration of diabetes nor type of treatment (insulin vs. oral antidiabetic drugs) related to cognitive function or accounted for the associations of thcy with cognitive function.

High tHcy has been associated with dementia (36-38), cerebrovascular disease (39-42), and brain atrophy $(43,44)$. This study adds to the literature that links high thcy to poorer cognitive performance and further indicates that cognitive performance is poorest in the presence of both high tHcy and type 2 DM. These results suggest that intervention studies designed to test whether treatment for high tHcy is efficacious in maintaining cognitive functioning (45-47) may be particularly important for individuals with type $2 \mathrm{DM}$.

\section{Acknowledgements}

Supported by National Heart, Lung, and Blood Institute (National Institutes of Health) grant 5R01-HL67358. The authors wish to thank Carole Johnston (Department of Pharmacology, University of Oxford) and Glynn Harvey (Nutritional Biochemistry Laboratory, Medical Research Council Human Nutrition Research, Cambridge, UK) for providing assay results. We also wish to thank Dawn Norris, Amanda Goodell, and Anna Sweeney (Department of Psychology, University of Maine) for their help in preparation of this manuscript.

\section{References}

1. Arnesen $\mathrm{E}$, Refsum $\mathrm{H}$, Bønaa $\mathrm{KH}$, Ueland $\mathrm{PM}$, Førde $\mathrm{OH}$, Nordrehaug JE. Serum total homocysteine and coronary heart disease. Int J Epidemiol 1995;24:704-9.
2. Bostom AG, Rosenberg IH, Silbershatz $H$, Jacques PF, Selhub J, D'Agostino RB, et al. Nonfasting plasma total homocysteine levels and stroke incidence in elderly persons: the Framingham Study. Ann Intern Med 1999; 131:352-5.

3. Bots ML, Launer LJ, Lindemans J, Hoes AW, Hofman A, Witteman JC, et al. Homocysteine and short-term risk of myocardial infarction and stroke in the elderly: the Rotterdam Study. Arch Intern Med 1999;159:38-44.

4. Bots ML, Launer LJ, Lindemans J, Hofman A, Grobbee DE. Homocysteine, atherosclerosis and prevalent cardiovascular disease in the elderly: the Rotterdam Study. J Intern Med 1997;242:339-47.

5. Ryan CM. Diabetes-associated cognitive dysfunction. In: Waldstein SR, Elias MF, editors. Neuropsychology of cardiovascular disease. Mahwah, NJ: Lawrence Erlbaum, 2001:61-82.

6. Hoogeveen EK, Kostense PJ, Beks PJ, Mackaay AJ, Jakobs C, Bouter LM, et al. Hyperhomocysteinemia is associated with an increased risk of cardiovascular disease, especially in non-insulin-dependent diabetes mellitus: a population-based study. Arterioscler Thromb Vasc Biol 1998;18:133-8.

7. Becker A, Smulders YM, van Guldener C, Stehouwer CD. Homocysteine as a risk factor in diabetes [abstract]. Clin Chem Lab Med 2005;43:A11.

8. Elias PK, Elias MF, D'Agostino RB, Cupples LA, Wilson PW, Silbershatz $\mathrm{H}$, et al. NIDDM and blood pressure as risk factors for poor cognitive performance. The Framingham Study. Diabetes Care 1997;20:1388-95.

9. Budge MM, de Jager C, Hogervorst E, Smith AD. Total plasma homocysteine, age, systolic blood pressure, and cognitive performance in older people. J Am Geriatr Soc 2002;50:2014-8.

10. Elias MF, Sullivan LM, D'Agostino RB, Elias PK, Jacques PF, Selhub J, et al. Homocysteine and cognitive performance in the Framingham Offspring Study: age is important. Am J Epidemiol 2005 (Aug).

11. Miller JW, Green R, Ramos MI, Allen LH, Mungas DM, Jagust WJ, et al. Homocysteine and cognitive function in the Sacramento Area Latino Study on Aging. Am J Clin Nutr 2003;78:441-7.

12. Ravaglia G, Forti P, Maioli F, Muscari A, Sacchetti L, Arnone G, et al. Homocysteine and cognitive function in healthy elderly community dwellers in Italy. Am J Clin Nutr 2003;77:668-73.

13. Teunissen $\mathrm{CE}$, Blom AH, Van Boxtel MP, Bosma $\mathrm{H}$, de Bruijn C, Jolles J, et al. Homocysteine: a marker for cognitive performance? A longitudinal follow-up study. J Nutr Health Aging 2003;7:153-9.

14. Dufouil C, Alperovitch A, Ducros V, Tzourio C. Homocysteine, white matter hyperintensities, and cognition in healthy elderly people. Ann Neurol 2003;53:214-21.

15. Elias MF, Robbins MA, Budge MM, Elias PK, Hermann BA, Dore GA. Studies of aging, hypertension and cognitive functioning: with contributions from the MaineSyracuse Study. In: Mattson MP, series editor, Costa PT, Siegler IC, volume editors. Advances in cell aging and gerontology, vol. 14. Recent advances in psychology and aging. Amsterdam: Elsevier, 2004:89-131.

16. Elias PK, Elias MF, Robbins MA, Budge MM. Blood pressure-related cognitive decline: does age make a difference? Hypertension 2004;44:631-6.

17. McKhann G, Drachman D, Folstein M, Katzman R, Price D, Stadlan EM. Clinical diagnosis of Alzheimer's disease: report of the NINCDS-ADRDA Work Group under the auspices of Department of Health and Human Services Task Force on Alzheimer's Disease. Neurology 1984;34: 939-44.

18. Radloff LS. The CES-D scale: a self-report depression scale for research in the general population. Appl Psychol Meas 1977;1:385-401. 
19. Folstein M, Folstein SE, McHugh PR. Mini-mental state: a practical method for grading the cognitive state of patients for the clinician. J Psychiatr Res 1975;12:189-98.

20. Shipchandler MT, Moore EG. Rapid, fully automated measurement of plasma homocysteine with the Abbott IMx analyser. Clin Chem 1995;41:991-4.

21. Tombaugh TN, Mclntyre NJ. The mini-mental state examination: a comprehensive review. J Am Geriatr Soc 1992;40:922-35.

22. American Diabetes Association. Diagnosis and classification of diabetes mellitus. Diabetes Care 2004;27: S5-10.

23. Cockcroft DW, Gault MH. Prediction of creatinine clearance from serum creatinine. Nephron 1976;16:31-41.

24. Leoncini G, Viazzi F, Parodi D, Vettoretti S, Ratto E, Ravera $M$, et al. Mild renal dysfunction and subclinical cardiovascular damage in primary hypertension. Hypertension 2003;42:14-8.

25. Stevens JP. Outliers and influential data points in regression analysis. Psych Bull 1984;95:334-44.

26. de Luis DA, Fernandez N, Arranz M, Aller R, Izaola O. Total homocysteine and cognitive deterioration in people with type 2 diabetes. Diabetes Res Clin Pract 2002; 55:185-90.

27. Smulders YM, Rakic M, Slaats EH, Treskes M, Sijbrands EJ, Odekerken DA, et al. Fasting and post-methionine homocysteine levels in NIDDM. Determinants and correlations with retinopathy, albuminuria, and cardiovascular disease. Diabetes Care 1999;22:125-32.

28. Selhub J, Bagley LC, Miller J, Rosenberg H. B vitamins, homocysteine, and neurocognitive function in the elderly. Am J Clin Nutr 2000;71:614S-20S.

29. Smith AD. Homocysteine, B vitamins, and cognitive deficit in the elderly. Am J Clin Nutr 2002;75:785-6.

30. Jacques PF, Selhub J, Bostom AG, Wilson PW, Rosenberg $\mathrm{IH}$. The effect of folic acid fortification on plasma folate and total homocysteine concentrations. N Engl J Med 1999:340:1449-54.

31. Wright CB, Lee H-S, Paik MC, Stabler SP, Allen RH, Sacco $\mathrm{RL}$. Total homocysteine and cognition in a tri-ethnic cohort: the Northern Manhattan Study. Neurology 2004; 63:254-60.

32. Kruman II, Culmsee C, Chan SL, Kruman Y, Guo Z, Penix $L$, et al. Homocysteine elicits a DNA damage response in neurons that promotes apoptosis and hypersensitivity to excitotoxicity. J Neurosci 2000;20:6920-6.

33. Lipton SA, Kim WK, Choi YB, Kumar S, D'Emilia DM, Rayudu PV, et al. Neurotoxicity associated with dual actions of homocysteine at the N-methyl-D-aspartate receptor. Proc Natl Acad Sci USA 1997;94:5923-8.

34. Parsons RB, Waring RH, Ramsden DB, Williams AC. In vitro effect of the cysteine metabolites homocysteic acid, homocysteine and cysteic acid upon human neuronal cell lines. Neurotoxicology 1998;19:599-603.
35. Schlaich MP, John S, Jacobi J, Lackner KJ, Schmieder RE. Mildly elevated homocysteine concentrations impair endothelium dependent vasodilation in hypercholesterolemic patients. Atherosclerosis 2000;153:383-9.

36. Clarke R, Smith $A D$, Jobst KA, Refsum $H$, Sutton $L$, Ueland PM. Folate, vitamin B12, and serum total homocysteine levels in confirmed Alzheimer disease. Arch Neurol 1998;55:1449-55.

37. McCaddon A, Davies G, Hudson P, Tandy S, Cattell H. Total serum homocysteine in senile dementia of the Alzheimer type. Int J Geriatr Psychiatry 1998;13:235-9.

38. Seshadri S, Beiser A, Selhub J, Jacques PF, Rosenberg $\mathrm{IH}, \mathrm{D}^{\prime}$ Agostino RB, et al. Plasma homocysteine as a risk factor for dementia and Alzheimer's disease. N Engl J Med 2002;346:476-83.

39. Malinow MR, Nieto FJ, Szklo M, Chambless LE, Bond G. Carotid artery intimal-medial wall thickening and plasma homocyst(e)ine in asymptomatic adults. The Atherosclerosis Risk in Communities Study. Circulation 1993;87: 1107-13.

40. Matsui T, Arai H, Yuzuriha T, Yao H, Miura M, Hashimoto $\mathrm{S}$, et al. Elevated plasma homocysteine levels and risk of silent brain infarction in elderly people. Stroke 2001; 32:1116-9.

41. Perry IJ, Refsum H, Morris RW, Ebrahim SB, Ueland PM, Shaper AG. Prospective study of serum total homocysteine concentration and risk of stroke in middle-aged British men. Lancet 1995;346:1395-8.

42. Selhub J, Jacques PF, Bostom AG, D'Agostino RB, Wilson PW, Belanger AJ, et al. Association between plasma homocysteine concentrations and extracranial carotidartery stenosis. N Engl J Med 1995;332:286-91.

43. den Heijer T, Vermeer SE, Clarke R, Oudkerk M, Koudstaal PJ, Hofman A, et al. Homocysteine and brain atrophy on MRI of non-demented elderly. Brain 2003;126: $170-5$.

44. Sachdev P. Homocysteine, cerebrovascular disease and brain atrophy. J Neurol Sci 2004;226:25-9.

45. Lewerin C, Matousek M, Steen G, Johansson B, Steen B, Nilsson-Ehle H. Significant correlations of plasma homocysteine and serum methylmalonic acid with movement and cognitive performance in elderly subjects but no improvement from short-term vitamin therapy: a placebo-controlled randomized study. Am J Clin Nutr 2005; 81:1155-62.

46. Toole JF, Malinow MR, Chambless LE, Spence JD, Pettigrew LC, Howard VJ, et al. Lowering homocysteine in patients with ischemic stroke to prevent recurrent stroke, myocardial infarction, and death: the Vitamin Intervention for Stroke Prevention (VISP) randomized controlled trial. J Am Med Assoc 2004;291:565-75.

47. van Asselt DZ, Pasman JW, van Lier HJ, Vingerhoets DM, Poels PJ, Kuin Y, et al. Cobalamin supplementation improves cognitive and cerebral function in older cobalamin-deficient persons. J Gerontol A Biol Sci Med Sci 2001;56A:M775-9. 
Copyright of Clinical Chemistry \& Laboratory Medicine is the property of Walter de Gruyter $\mathrm{GmbH}$ \& Co. KG.. The copyright in an individual article may be maintained by the author in certain cases. Content may not be copied or emailed to multiple sites or posted to a listserv without the copyright holder's express written permission. However, users may print, download, or email articles for individual use. 